\title{
Selection of urban community service paths for the old during harmonious society construction
}

\author{
Ping Liang \\ Guangxi University of Science and Technology, Liuzhou, 545005, China
}

Keywords: harmonious society; urban community; community service for the old; path

\begin{abstract}
With era development, population aging becomes increasingly serious. There are more than more aging and empty-nest phenomena. Thus, the number of the old who cannot completely look after themselves and need to be looked after is on the rise. Based on this background, firstly, this paper simply summarizes the connotation of community service for the old, community service system for the old and current situation of urban community service for the old. Secondly, this paper discusses the importance of boosting urban community service system for the old during harmonious society construction. Finally, this paper deeply discusses selection of urban community service paths for the old during harmonious society construction.
\end{abstract}

\section{Introduction}

According to the data of the $6^{\text {th }}$ nationwide census, the proportion of the old has reached $13.26 \%$. The number of the people with the age exceeding 60 is 178 million. The number of family members in China decreases gradually. The population of the old increases progressively. Rural areas develop toward cities and present diversified development trend. These make more and more families unable to afford the duty to support the old. Thus, the demand of the old for national welfare and service policies increases. More families push providing for the old to the society, which gives rise to huge pressure to the state.

\section{Overview of community services for the old}

\section{Concept and features of community services for the old}

Community service for the old means various kinds of strength serving the old in the community are joined to assist families in providing for the old. They main adopt door-to-door service and acceptance of trusteeship of the old to help families to look after the old. In this way, the old live in their own homes and receive the care of their children then they are free. When their children are busy in work, they will receive services from the community. Community services for the old mainly include daily care, recreational activities, comforting their soul and proving medical services. For example, the community can deliver the meal for the old, look after the sick old people and help then do cleaning.

Features of community service for the old: the old can enjoy considerate care from their children when they are free and can enjoy various services supplied by service organizations in the community. The charge of community service organizations for the old is based on welfare. The charging standard is set according to living conditions of the old. For the poor old people, they will enjoy free services.

Community service for the old is different from other service ways for the old as follows: for family provision for the old, it enjoys the services from the family and the community; for social provision for the old, it introduces the service contents in social institutions for the old. It synthesizes excellent parts of family provision for the old and social provision for the old and applies these advantages in community service for the old. This is a new way to provide for the old in the face of increasingly serious aging problem.

Connotation of social provision system for the old

New social provision system for the old aims to solve the increasingly serious aging problem and make the old enjoy their twilight years. It complies with current economic development. The scope covers the old nationwide. The old are provided with help in life, health care, recreational activities, spiritual comfort and trusteeship etc. The government's guiding role is exerted through supporting 
system, service standard and management. The system mobilizes social force to participate, continuously innovates for the service contents, perfects service system and meets more and more requirements of the old with the normalized system as the guarantee.

\section{Current situation of urban community service for the old}

Cities and towns own certain service sources for the old, but the supporting facilities are imperfect. Cities have relatively perfect service system for the old, state-run welfare houses for the old, private service centers for the old with complete facilities, hourly employees to look after the old and full-time nurses. However, due to different economic conditions, only few old people can enjoy costly apartments for the old and first-class medical services. Most old people select to live at home. Some old people who live at home are inconvenient in movement. Thus, they need medical and meal delivery services. China is still in the initial stage of service for the old. The system is still not perfect. There is the lack of professional personnel to service the old. Besides, the service items are few and can only cover some groups. There is still a long way for the service for the old.

\section{Importance of boosting community service for the old during harmonious society construction}

\section{Company with the needs of the old under the background of aging population}

The old spend most time in the community. They reside and live in the community. As they get older and older, they need more diversified community services to meet all they need. One-stop service for the old in the community can make the old have the sense of belonging. Community service for the old has the features of wide coverage and convenient operations. In the past, there were many family members. Currently, most big families are replaced by small families. Many old people do not live with their children. Thus, the number of empty-nest old people is on the rise. This gives rise to great inconvenience to life and medical treatment of the old. Perfecting community service system for the old can solve the problem of providing for the old to some extent and meet the needs of the old. It is an inevitable requirement for development of socialism.

\section{Provide important supplement for perfecting China's social provision insurance system for the old}

China is still a developing country. The economic development level has a large gap with that of developed countries. The service system for the old is still not perfect. Existing welfare facilities for the old cannot meet quality and quantity needs of the old. Meanwhile, there is the lack of professional nursing personnel in the service institutions for the old. High expenditure for the service also makes many old people dare not live in the institutions. Some old people with good economic conditions can accord the expenses, but they are unwilling to live in such place due to deep-rooted traditional thought. Some old people who live in the institution will be isolated with the society and feel lonely and helpless. So, to perfect China's servicer system for the old, community service fore the old must be developed to solve the problem of urban service for the old.

\section{Contribute to driving socialist spiritual civilization construction with Chinese characteristics}

To make the old happier in their twilight years and enjoy one-stop comfortable community services is the demand of China to construct socialist spiritual civilization and also the requirement for China to pursue higher-level service for the old. Perfect community service items for the old include recreational activities, medical treatment services, door-to-door housekeeping, emotional comfort, daily care and meal delivery etc. thoughtful services are provided for the old in various aspects so that the old can fully feel social warmth, which can promote social civilization progress.

Contribute to maintaining social stability and promoting harmonious society construction

In the primary stage of socialism, China enters the aging society. Due to underdeveloped economy, it is hard to bear high-quality and high-quantity services for the old. Thus, China needs to construct a new system for the old which should comply with national situations to alleviate economic pressure of the government. The community service for the old accords with the requirements in this stage, creates harmonious environment for China to establish service system for the old in new era and further promotes harmonious and stable social development. 


\section{Paths of urban community service for the during harmonious society construction}

\section{Enhance publicity of service for the old and value aging problem ideologically}

Everyone will experience the old stage. Chongqing has been an aging city. As a new cause, service fore the old also has large development space. On the one hand, it is required to enhance publicity of service for the old and make community residents fully realize the importance of solving the problem of supporting the old for Chinese social development. On the other hand, community workers should improve their consciousness, value the services fro the old ideologically and promote practice. Similarly, successful practical activities can well publicize the service for the old. So, it is necessary to share successful experience in supporting the old to the society so that more people can realize the importance.

Perfect community service system for the old and provide institutional guarantee for the old

The family is the residence of the old, while the community is their living space. Establishing perfect community service system for the old has the social inevitability. In current stage, city community construction in China is not mature. To better establish community service system for the old, the following aspects should be done. Firstly, sufficient manpower and perfect system should serve as the guarantee in the aspects of infrastructure, personnel placement and system perfection. Secondly, it is required to establish information file for the old, know their needs, physical conditions and addresses ands arrange the volunteers suitable for them in combination of the files of the volunteers. In this way, the needs of the old and the services of the volunteers can be perfectly combined. In addition, due to the nature of volunteers, they cannot meet all needs of the old in the community. So, the community should contact paid nursing institutions for the old to provide services for some old people. Thirdly, it is required to improve medical service level of the community hospital and provide door-to-door treatment services for the old. In this way, the old can treat minor illness in the community. Finally, it is necessary to organize abundant recreational activities for the old, improve their enthusiasm for participation and make them enjoy their twilight years happily.

\section{Actively expand capital sources and provide sufficient capital support}

Strong economic support can drive development of community service for the old. A large quantity of funds is needed to construct perfect community service system for the old. Thus, capital support form all sectors of society is needed.

Firstly, it is required to give play to financial strength of the government, increase expenditure of social security funds and make the government become the main capital provider.

Secondly, encourage non-profit organization to join. They have reliable capital source. Besides, due to their non-profit nature, they have wide mass base. So, they can utilize their strength to mobilize the masses to inject funds for community service construction for the old.

Thirdly, mobilize the strength of profit organizations to serve the community. According to the survey results, the old are willing to pay the expense for the services they need. This can promote development of community service for the old. In the process of developing community service for the old, the units and individual involved should benefit from it. It is required to encourage them to construct community service for the old so as to drive development of community service for the old.

Fourthly, integrate existing service sources for the old and effectively utilize these resources, including the site and facilities. This can not just give full play to the purpose of existing resources, but also reduce repeated expenditure.

Sixthly, overall social planning fund in pension insurance funds can be taken out as the fund of community services for the old. To provide basic living guarantee for the old, the state establishes pension insurance fund system. The fund used in community service for the old aims to serve the old in the community. The overall objectives are consistent. It is very feasible to take out proper funds from pension funds for community services for the old.

Enrich supporting resources and facilities from the practical needs of the old

Perfection of infrastructure of community service for the old directly concerns the ability of the community to support the old. The facilities here refer to the facilities for leisure and recreation and community hospitals. During constructing recreational facilities, it is required to start with practical 
situations of the old in the community, design and adjust the facilities suitable for the needs of the old. To enrich medical resources of the community, firstly, it is required to start from the whole medical resources in the community and integrate existing medical resources, including state-run primary hospitals, private medical institutions and individual clinics. Besides, it is required to establish cooperation relationship with surrounding large medical institutions to reduce miscellaneous hospitalization procedures and fully utilize medical resources.

\section{Enhance quality training for the service personnel and improve whole quality of the service team}

With era development, the old are not satisfied with basic material needs. So, they start to pursue spiritual and mental satisfaction. Thus, diversification and hierarchy appear for the service for the old. In the face of various needs of the old, the community needs to employ professional service personnel with high morality, rich cultural connotation, strong professional skills and good psychological quality. Therefore, during constructing new community service system for the old, firstly, it is required to communicate with colleges and universities, add relevant professional courses in the curriculum setting so as to make professional knowledge of community service for the old fused in social teaching system. Secondly, the employment standard of community service for the old should be set so that the service level of the personnel can gain institutional affirmation. Thirdly, it is required to enhance training force for existing service personnel and make them receive standard and systematical professional knowledge so as to improve overall quality of the service team.

\section{Apply modern scientific and technological resources as well as information technology ad improve service management level}

It is required to start with the needs of the old in the community, provide thorough daily care services, take full advantage of existing service sources, integrate resource superiority and adopt multiple ways (perfecting the file of the old, service hotline, multimedia network service information and service propaganda) to establish perfect the community service network for the old and community platform, give play to the publicity and guiding roles of the information platforms and provide superior and comprehensive services fort the old in the community. It is also necessary to establish complete electronic information file system for the old in the community, give play to the effects of multimedia, make nursing institutions for the old outside the community rapidly know the information and needs of the old in the community and make the family, community and nursing institutions for the old connected solely to provide services for the old in the community more efficiently and reliably.

\section{Conclusions}

In China, the problem of population aging becomes more and more outstanding and has become a significant issue restricting China's social development. Thus, the state needs to mobilize the strength of the government, society and market to explore a way to solve the problem of aging population and establish a new service system for the old with family service for the old as the key, community service as the support and various nursing institutions for the old as assistance to meet the need to solve the aging problem and make the service for the old ensured.

\section{References}

[1] Lu Dandan, Study on demand and supply of medical treatment and health for the old in urban community service for the old [J]. Reform \& Opening, 2013, 02:84

[2] Shu Lijuan, Community service for the old - new choice for city and town service mode for the old [J]. Knowledge-based Economy, 2013, 03:78

[3] Ji Pengfei, Current situation and development of home-based care for the old in urbanization course - case study on Suzhou community home-based care for the old [J]. Theory Research, 2013, 22:104-105

[4] Chen Yuangangm Xie Jintao, Liu Bo, Study on construction of urban community service system for the old - case study of Chongqing [J]. Journal of Chongqing Technology and Business University (Social Science Edition), 2010, 03:72-78 